\title{
Reply to correspondence letter from Dr. Althaf Ansary for Transport of infants with congenital heart disease
}

\author{
Neelam Gupta $\cdot$ Neil Patel
}

Received: 25 September 2014 / Accepted: 1 October 2014 / Published online: 21 October 2014

(C) Springer-Verlag Berlin Heidelberg 2014

Thanks for your comment and interest in the published article [2]. In our study, antenatally diagnosed and postnatally diagnosed congenital heart disease groups were contemporary. We agree with A. Ansary that there has been a significant improvement in antenatal diagnosis of congenital heart disease; this is reflected in our study, which covers a time period later than the study by Chew et al. [1] and reflects higher percentage of antenatally diagnosed congenital heart disease in the same population.

The retrospective nature of our study would not allow us to determine whether higher threshold for use of invasive ventilation and inotrope was given during neonatal transfers. Though we can speculate that there is usually a low threshold for intubation and ventilation during neonatal transfers, as transfers may be associated with clinical deterioration. This is especially relevant during air transport where the scope of intervention during transfer is limited. Similarly, in an infant suspected of congenital heart disease and needing transfer, permissive hypotension would not be allowed though this may be a practice in a safe environment of neonatal unit. In our cohort, antenatally diagnosed infants were referred earlier and transferred shorter distances, often without respiratory support or inotropes. Those diagnosed postnatally were born at nontertiary centers, without specialist neonatal or cardiac services, presented later during transfer from geographically distant locations. These factors in postnatally diagnosed infants may account for cardio-respiratory instability and hence significantly higher rates of invasive ventilation and inotropes used in this group.

\section{References}

1. Chew C, Stone S, Donath SM, Penny DJ (2006) Impact of antenatal screening on the presentation of infants with congenital heart disease to a cardiology unit. J Paediatr Child Health 42(11):704-708

2. Gupta N, Leven L, Stewart M, Cheung M, Patel N (2014) Transport of infants with congenital heart disease: benefits of antenatal diagnosis. Eur J Pediatr 173(5):655-60

Communicated by Peter de Winter

This paper is a reply to the correspondence letter which can be found at http://dx.doi.org/10.1007/s00431-014-2438-8

N. Gupta $(\square)$

John Radcliffe Hospital, Oxford OX39DU, UK

e-mail: neelam27@doctors.org.uk

N. Patel

Institute-Royal Children's Hospital, Melbourne, Australia 